\title{
PAPER
}

\section{Novel targets for the control of secretory diarrhoea}

\section{J G Farthing}

Gut 2002;50(Suppl III):iii 15-iii 18

Secretory diarrhoea continues to be a major clinical problem worldwide. It is now recognised that the enteric nervous system plays an important role in the pathogenesis of enterotoxin mediated intestinal secretion, which has resulted in the identification of novel therapeutic targets for the treatment of acute watery diarrhoea.
Correspondence to: Prof. M J G Farthing, Faculty of Medicine, University of Glasgow, 12 Southpark Terrace, Glasgow G12 8LG, UK; m.farthing@

clinmed.gla.ac.uk
A cute diarrhoea has a major impact on morbidity and mortality worldwide, with as many as four billion cases occurring each year. In economically deprived parts of the world such as the Indian subcontinent, Africa, and Latin America, children may experience between three and 10 episodes of diarrhoea each year. Even in the wealthy industrialised world, acute diarrhoea in children has a significant clinical impact. Intestinal infection is the most common cause of diarrhoea worldwide and is responsible for the deaths of 3-4 million individuals each year, the majority of whom are preschool children. Acute infectious diarrhoea is a continuing problem in industrialised countries, principally through foodborne transmission.

Most of the deaths from acute infectious diarrhoea result from excessive fluid and electrolyte losses that result in dehydration and acidosis. Thus, the majority of these deaths are avoidable as long as fluid and electrolyte losses are replaced promptly. Oral rehydration therapy with glucoseelectrolyte solutions has saved the lives of millions of children since it was first introduced about 30 years ago and remains the mainstay of therapy for acute watery diarrhoea. However, in high volume watery diarrhoea such as cholera, replacing fluid losses orally still presents a major challenge for carers and health care professionals.

During the past two decades there has been a continuing search for drugs that might inhibit the secretory process within the enterocyte. Although a number of candidates have emerged none have found a place in the routine management of secretory diarrhoea. However, recent studies have identified new potential targets for antisecretory drugs which include receptors in the enteric nervous system (ENS).

\section{MECHANISMS OF INTESTINAL SECRETION}

Diarrhoea is characterised by an increase in stool frequency and a change in stool consistency. However, both symptoms can occur in functional disorders such as irritable bowel syndrome; it is more precise therefore to define diarrhoea as an increase in stool weight, which in Western countries is usually taken as a stool weight $>200 \mathrm{~g} / 24 \mathrm{~h}$. Diarrhoea occurs as a result of increased intestinal secretion or decreased intestinal absorption, but in some diseases diarrhoea may result from a combination of these mechanisms. ${ }^{12}$

\section{Enterotoxins and the enterocyte}

Intestinal secretory processes in bacterial diarrhoea are commonly activated by enterotoxins. The conventional mechanism involves a ligandreceptor interaction at the apical membrane of the enterocyte, activation of an intracellular cascade of "second messengers", and finally a series of changes in ion transport that usually culminate in a net efflux of chloride ions into the gut lumen. Sodium ions follow to maintain electroneutrality and water moves into the lumen passively to maintain isotonicity. The $\mathrm{A}_{1}$ subunit of cholera toxin (CT) is a nicotinamide adenine dinucleotide (NAD) dependent ribosyl transferase which covalently links adenosine diphosphate (ADP) ribose to guanine nucleotide binding protein ( $G$ protein); this activates $G_{s^{\prime}}$ the catalytic unit of the enzyme adenylate cyclase. ${ }^{34}$ This results in an increase in intracellular cyclic AMP which through a series of intermediate steps results in phosphorylation of the transmembrane chloride channel protein with opening of the chloride channel.

There are other important bacterial enterotoxins, particularly those produced by Escherichia coli. $E$ coli heat labile toxins (LT1 and LT2) are a group of proteins that are closely related structurally, functionally, and immunologically to $\mathrm{CT}^{3}{ }^{4}$ Like CT, E coli LT has A and B subunits and activates adenylate cyclase by catalysing ADP ribosylation of $\mathrm{G}_{\mathrm{s}}$. E coli also produces a group of low molecular weight enterotoxins that are heat stable (ST). ST differs from LT and CT in that it activates guanylate cyclase with an associated increase in the intracellular cyclic guanosine monophosphate (cGMP) concentrations.

Enterotoxins and the enteric nervous system It is now well established that the ENS is involved in the promotion of intestinal secretory processes. ${ }^{5}$ A large number of neurotransmitters have now been identified in the ENS, many of which are likely to be involved in these processes (table 1) and are therefore potential targets for pharmacotherapy of watery diarrhoea. Neuronal pathways have been implicated in pertubations of intestinal transport associated with bacterial

Abbreviations: $C T$, cholera toxin; ENS, enteric nervous system; LT, heat labile toxin; ST, heat stable toxin; VIP. vasoactive intestinal peptide 
Table 1 Established and putative neurotransmitters in the enteric nervous system

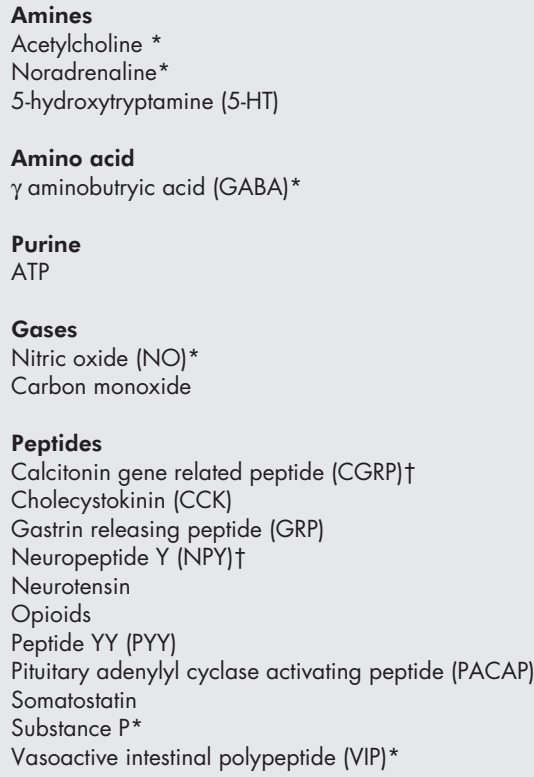

infection, and there is increasing evidence that CT, LT, and ST enterotoxins produce their secretory effects at least in part via a neuronal reflex arc.

\section{Cholera toxin}

CT induced secretion in mammalian intestine is inhibited by the neurotoxin, tetrodotoxin, the nicotinic receptor antagonist, hexamethonium, and lignocaine, a local anaesthetic. It is now thought that CT secretion is mediated by a neuronal reflux arc involving a sensory afferent neurone which is probably cholinergic, an interneurone in the myenteric plexus which has substance $\mathrm{P}$ as the neurotransmitter, and a secretory type 1 neurone which is likely to be VIPergic. There is also evidence that CT can release a variety of endogenous secretagogues including 5-HT, neurotensin, and prostaglandins. ${ }^{6-9}$

CT releases 5-HT from enterochromaffin cells; intraluminal 5-HT concentrations correlate closely with the magnitude of intestinal fluid secretion. ${ }^{10}$ We have recently shown that 5-HT itself can modulate 5-HT release from enterochromaffin cells via $5-\mathrm{HT}_{3}$ receptors which are known to exist on enterochromaffin cells. ${ }^{11}$ Thus, autoregulation of enterochromaffin cells by 5 -HT is likely to be important both in physiological and pathophysiological states.

5-HT released from enterochromaffin cells is thought to activate the afferent limb of the neuronal reflex via $5-\mathrm{HT}_{3}$ and possibly $5-\mathrm{HT}_{4}$ neuronal receptors. The effector limb of the neuronal reflex probably completes the neuronal pathway by releasing vasoactive intestinal peptide (VIP), which then binds to specific receptors on the basolateral membrane and activates an adenylate cyclase-cAMP intracellular secretory pathway. Interneurones appear to propagate the secretory effects of CT distally in the small intestine.

Confirmatory evidence that the 5-HT initiated neural secretory reflex is important in cholera comes from pharmacological inhibition studies in mammalian intestine. ${ }^{12-14}$ However, the most profound inhibitory effects can only be achieved when a 5-HT antagonist is administered prior to exposure to CT. Human studies however, have produced conflicting results. The $5-\mathrm{HT}_{2}$ receptor antagonist, ketanserin, given in combina- tion with the $5-\mathrm{HT}_{3}$ receptor antagonist, ondansetron, failed to reverse cholera secretion, as did the $5-\mathrm{HT}_{3}$ receptor antagonist, tropisetron. ${ }^{15}$ The $5-\mathrm{HT}_{3}$ receptor antagonist, alosetron increased basal sodium and fluid absorption but failed to significantly reduce secretion in a human model of cholera. ${ }^{16}$ However, a recent study with the $5-\mathrm{HT}_{3}$ receptor antagonist, granisetron reversed fluid and chloride ion secretion to net absorption. ${ }^{17}$

Substance P antagonists reduce CT induced fluid secretion in a dose dependent manner in mammalian intestine, again confirming a possible role for this neurotransmitter. ${ }^{18}$ Unlike the $5-\mathrm{HT}_{3}$ receptor antagonist, granisetron, the substance $\mathrm{P}$ antagonists were not able to reverse net secretion to absorption.

The importance of VIP in CT induced fluid secretion is also supported by inhibition studies. The VIP antagonist [4Cl-D$\mathrm{Phe}^{6}$ Leu $\left.^{17}\right]$ VIP converted fluid secretion in rat jejunum to net absorption. ${ }^{19}$ Similarly, the sigma receptor agonist, igmesine, which reverses VIP induced increases in short circuit current in mouse ileum mounted in Ussing chambers, reduced CT induced secretion in rat jejunum in vivo and was effective when given both before and following establishment of the secretory state. ${ }^{20}$

These observations are consistent with a neural reflex involving 5-HT neural receptors on an afferent sensory nerve, an interneurone in the myenteric plexus and a secretory VIPergic neurone. These studies have clearly identified a number of potential novel targets for antisecretory pharmacotherapy.

\section{E coli enterotoxins}

LT has marked structural homogeneity with CT and is known to activate adenylate cyclase in enterocytes. LT, however, does not release 5-HT from enterochromaffin cells in the small intestine, and the secretory state induced by this toxin is not inhibitable by 5 -HT receptor antagonists. ${ }^{21}$ Similarly, LT secretion is not inhibited by substance P antagonist although the sigma receptor ligand, igmesine does inhibit both CT and LT secretion. Despite these differences between CT and LT, the action of the latter is inhibited by hexamethonium and lignocaine, supporting the view that the ENS is involved in LT secretion. We have also recently shown that $\mathrm{LT}$, like $\mathrm{CT}$, releases VIP, again indicating that the secretory neuronal afferent is a VIPergic nerve.

The secretory activity of ST also appears to involve the ENS, as fluid secretion is inhibited by tetrodotoxin, lignocaine, and hexamethonium. ${ }^{22}$ However, like LT, 5-HT release from enterochromaffin cells does not appear to be involved. NO however, has been implicated in ST induced secretion, although neither tetrodotoxin nor the nitric oxide synthetase inhibitor, L-NAME, affect ST induced changes in short circuit current in muscle stripped preparations of pig jejunum and colon. This would support the importance of the myenteric plexus in enterotoxin induced secretory events.

\section{POTENTIAL NOVEL TARGETS FOR CONTROLLING SECRETORY DIARRHOEA}

Inhibition of intestinal secretion

5-HT receptor antagonists

The demonstration that 5-HT has an important role in triggering the neural reflex clearly identifies an important potential new target for pharmacotherapy. $5-\mathrm{HT}_{2}, 5-\mathrm{HT}_{3}$, and $5-\mathrm{HT}_{4}$ receptors all appear to be involved as secretion is inhibited by specific antagonists at these receptors. However, the potential for using these targets for therapy in human disease currently appears to be limited. Only CT (not LT or ST) has been shown to depend on 5-HT to activate the local neuronal reflex in the ENS, and 5-HT antagonists could only be used prophylactically as they appear to have little or no effect once the secretory state is established. 


\section{Sigma agonists}

The sigma receptor agonist, igmesine is the only antisecretory agent that we have tested to date that inhibits both CT and the $E$ coli enterotoxins. ${ }^{20}$ Sigma receptors are known to be present on nerves in the ENS and this would seem to be a potentially useful class of drugs to pursue for the treatment of secretory diarrhoea in humans. Although igmesine is not currently being developed for the treatment of secretory diarrhoea, other more potent agents in this class are under evaluation.

\section{Promotion of intestinal absorption \\ Somatostatin}

In addition to endogenous secretagogues within the gut mucosa and ENS, there are also endogenous absorbagogues. Somatostatin and its receptors are found throughout the alimentary tract and are known to be important in the physiological regulation of gastric and pancreatic secretion. The role of somatostatin in controlling secretory and absorptive processes in the intestine is less well defined. However, somatostatin is present in some intestinal neurones which are considered to be proabsorptive. There is therefore the potential to use somatostatin or one of the longer acting somatostatin analogues in the control of secretory diarrhoea.

Octreotide, the somatostatin analogue, has been shown to reduce intestinal effluent in short bowel syndrome, but has its most important clinical effects on intestinal secretion induced by neuroendocrine tumours, particularly VIPoma, carcinoid tumours, and gastrinoma. ${ }^{23}{ }^{24}$ In this situation however, somatostatin analogues are thought to have their primary action on neuroendocrine tumours by inhibiting release of secretagogues, namely VIP and 5-HT. However, there are reports that somatostatin and its analogues can inhibit intestinal secretion in VIPoma patients in the absence of a reduction in plasma VIP, indicating that the antisecretory activity may be operating through a direct effect, either on the ENS or on the enterocyte itself.

Octreotide has been evaluated in a small, randomised study in patients with cholera who were treated conventionally (fluid replacement, antibiotics), but who in addition were randomised to receive octreotide or placebo. ${ }^{25}$ There was a tendency for stool volume and the duration of diarrhoea to be reduced in the octreotide group, although overall the results were not impressive.

\section{Enkephalinase inhibitor}

Another important family of proabsorptive neurotransmitters in the ENS are the enkephalins. ${ }^{26}$ Enkephalinergic nerves have been identified extending to the basolateral membrane of enterocytes, and enkephalins have proabsorptive activity. They have been shown to decrease short circuit current and potential difference across isolated rabbit ileal mucosa. The effect is blocked by tetrodotoxin, but not by adrenaline or atropine, indicating a role for enkephalins as preganglionic neurotransmitters within the gastrointestinal tract. Enkephalins appear to have their major effect through delta receptor activation that induces a selective increase in chloride absorption. Enkephalins have also been shown to reduce CT induced small intestinal secretion, at least in part, by inhibiting adenylate cyclase through delta opioid receptors.

The proabsorptive, antisecretory activity of endogenous enkephalins has been exploited in a major new drug development. ${ }^{26}{ }^{27}$ Endogenous enkephalins are rapidly degraded by a membrane bound metalloproteinase, enkephalinase. This enzyme is abundant in the gastrointestinal tract and accounts for over $85 \%$ of the hydrolysis of methionine and leucine enkephalins. A potent inhibitor of enkephalinase has been developed; it was originally known as acetorphan but was recently renamed racecadotril. This agent has been shown to have antisecretory activity against several secretagogues, including CT and prostaglandins, ${ }^{28}$ and is effective in the clinical management of acute diarrhoea in both adults ${ }^{29}$ and children. ${ }^{30-32}$ This novel approach to the pharmacotherapy of secretory diarrhoea would appear to be promising, and has a major advantage over standard opiate antidiarrhoeal agents in that it does not produce enteropooling and rebound constipation.

\section{SUMMARY}

Acute watery diarrhoea has a high morbidity and mortality worldwide. Intestinal infection is the major cause of acute diarrhoea, although the prevalence of individual pathogens varies according to geographic location. In many countries in the industrialised world, reports of intestinal infections continue to increase; these are largely related to waterborne and foodborne outbreaks. Acute diarrhoea may be caused by increased intestinal secretion, commonly as a result of infection with enterotoxin producing organisms (enterotoxigenic $E$ coli, Vibrio cholerae) or by decreased intestinal absorption as a result of infection with organisms that damage the intestinal epithelium (enteropathogenic E coli, Shigella sp., Salmonella sp.). Although oral rehydration therapy has reduced the mortality associated with acute diarrhoea, the diarrhoea attack rate remains unchanged and stool volume often increases during the rehydration process. There has therefore been a search for more than 20 years for agents that will directly inhibit intestinal secretory mechanisms and thereby reduce stool volume. Research during the past decade has highlighted the importance of neurohumoral mechanisms in the pathogenesis of diarrhoea, notably the role of 5-hydroxtryptamine, substance $\mathrm{P}$, vasoactive intestinal polypeptide, and neural reflexes within the enteric nervous system. Cholera toxin and $E$ coli enterotoxins are known to invoke these mechanisms in diarrhoea pathogenesis and there is now increasing evidence that rotavirus infection also activates a neural secretory pathway. This new dimension of intestinal pathophysiology has already exposed possible novel targets for antisecretory therapy, namely 5-HT receptor antagonists, substance P antagonists, and the possibility for potentiating the proabsorptive effects of endogenous enkephalins by use of enkephalinase inhibitors. There is now a real possibility that antisecretory therapy will become more widely available for the teatment of watery diarrhoea, although it is likely that this will always remain an adjunct to oral rehydration therapy. Authors' affiliations

\section{REFERENCES}

1 Farthing MJG. Acute diarrhea: pathophysiology. In: Gracey M, Walker-Smith JA, eds. Diarrheal disease. Vol. 38. Vevey: Lippincott-Raven Publishers, 1997:55-71.

2 Farthing MJG. Pathophysiology of infective diarrhoea. Eur J Gastroenterol Hepatol 1993:5:796-807.

3 Rao MC. Molecular mechanisms of bacterial toxins. In: Farthing MG Keusch GT, eds. Enteric infection. London: Chapman \& Hall, 1989:87-104

4 Field $M$, Fao MC, Chang EB. Intestinal electrolyte transport and diarrhoeal disease. N Engl J Med 1989;321:879-83.

5 Hubel KA. Intestinal nerves and ion transport: stimuli, reflexes and responses. Am J Physiol 1985;248:G261-71.

6 Jodal M. Neuronal influence on intestinal transport. J Intern Med 1990;228: 125-32

7 Cassuto J, Fahrenkrug J, Jodal M, et al. Release of vasoactive intestinal polypeptide from the cat small intestine exposed to cholera toxin. Gut $1981 ; 22: 958-63$

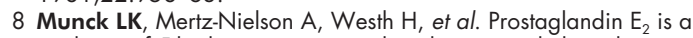
mediator of 5-hydroxtryptamine induced water and electrolyte secretion in the human jejunum. Gut 1988:29:1337-41.

9 Beubler E, Kollar G, Saria A, et al. Involvement of 5-hydroxytryptamine, prostaglandin $E_{2}$ and cyclic adenosine monophosphate in cholera toxin-induced fluid secretion in the small intestine of the rat in vivo. Gastroenterology 1989:96:368-76.

10 Bearcroft CP, Perrett D, Farthing MG. 5-hydroxytryptamine release into human jejunum by cholera toxin. Gut 1996;39:528-31. 
11 Turvill JL, Connor P, Farthing MUG. Inhibition of cholera toxin-induced 5 - $\mathrm{HT}$ release by the 5-HT3 receptor antagonist, granisetron, in the rat. $\mathrm{Br}$ J Pharmacol 2000;130:1031-6.

12 Beubler E, Horina G. 5- $\mathrm{HT}_{2}$ and $5-\mathrm{HT}_{3}$ receptor subtypes mediate cholera toxin-induced intestinal fluid secretion in the rat. Gastroenterology 1990:99:83-9.

13 Buchheit KH. Inhibition of cholera toxin-induced intestinal secretion by the 5- $\mathrm{HT}_{3}$ receptor antagonist ICS 205-930. Arch Pharmacol 1989:339:704-5.

14 Mourad FH, O'Donnell LD, Dias JA, et al. Role of 5-hydroxytryptamine type 3 receptors in rat intestinal fluid and electrolyte secretion induced by cholera and Escherichia coli enterotoxins. Gut 1995;37:340-5.

15 Ehere AJ, Hinterleitner TA, Petritsch W, et al. Effect of 5-hydroxtryptamine antagonists on cholera toxin-induced secretion in the human jejunum. Eur J Clin Invest 1994;24:664-8.

16 Bearcroft CP, Andre E, Farthing MG. In vivo effects of the $5-\mathrm{HT}_{3}$ antagonist alosetron on basal and cholera toxin-induced secretion in the human jejunum: a segmental perfusion. Aliment Pharmacol Ther 1997;11:1109-14.

17 Turvill JL, Farthing MG. Effect of granisetron on cholera toxin-induced enteric secretion. Lancet 1997;349:1293.

18 Turvill JL, Connor P, Farthing MG. Neurokinin 1 and 2 receptors mediate cholera toxin secretion in rat jejunum. Gastroenterology 2000;1 19:1037-44

19 Mourad FH, Nassar C. Effect of vasoactive intestinal peptide (VIP) antagonism on rat jejunal fluid and electrolyte secretion induced by cholera and Escherichia coli enterotoxins. Gut 2000;47:382-6.

20 Turvill JL, Kasapidis P, Farthing MU. The sigma ligand, igmesine, inhibits cholera toxin and Escherichia coli enterotoxin induced jejunal secretion in the rat. Gut 1999:45:564-9.

21 Turvill JL, Farthing MG. Selective 5-hydroxytryptamine type $4\left(5-\mathrm{HT}_{4}\right)$ antagonist inhibits cholera toxin (CT) but not E.coli heat labile toxin (LT)-induced secretion. Gastroenterology 1996;110:A368.
22 Eklund $\mathrm{S}$, Jodal $M$, Lundgren $\mathrm{O}$. The enteric nervous system participates in the secretory response to the heat stable enterotoxins of Escherichia coli in rats and cats. Neuroscience 1985;14:673-81.

23 Farthing MJG. The role of somatostatin analogues in the treatment of refractory diarrhoea. Digestion 1996;57:107-12.

24 Fried $M$. Octreotide in the treatment of refractory diarrhea. Digestion 1999:60:42-6.

25 Abbas Z, Moid I, Khan AH, et al. Efficacy of octreotide in diarrhoea due to Vibrio cholerae: a randomized, controlled trial. Ann Trop Med Parasitol 1996;90:507-13.

26 Turvill JL, Farthing MG. Enkephalins and enkephalinase inhibitors in intestinal fluid and electrolyte transport. Eur J Gastrohepatol 1997;9:877-80.

27 Farthing MJG. Enkephalinase inhibition: a rational approach to anti-secretory therapy for acute diarrhoea. Aliment Pharmacol Ther 1999;13(suppl 6): 1-2.

28 Primi MP, Beuno L, Baumer P, et al. Racecadotril demontrates intestinal anti-secretory activity in vivo. Aliment Pharmacol Ther 1999;13/suppl 6):3-7.

29 Hamza H, Khalifa HB, Baumer P, et al. Racecadotril versus placebo in the treatment of acute diarrhoea in adults. Aliment Pharmacol Ther 1999;13(suppl 6):15-19.

30 Turck D, Berard H, Fretault N, Lecomte JM. Comparison of racecadotril and loperamide in children with acute diarrhoea. Aliment Pharmacol Ther 1999;13(suppl 6):27-32.

31 Cezard JP, Duhamel JF, Meyer M, et al. Efficacy and tolerability of racecadotril in acute diarrhea in children. Gastroenterology $2001 ; 120: 799-805$

32 Salazar-Lindo E, Santisteban-Ponce J, Chea-Woo E, Gutierrez M. Racecadotril in the treatment of acute watery diarrhea in children. N Engl J Med 2000;343:463-7. 